\title{
Lichens as biomonitors at indoor environments of primary schools
}

\author{
N. Canha, M. Almeida-Silva, M. C. Freitas, S. M. Almeida and H. Th. Wolterbeek
}

Link Out to this Article at Instituto Politécnico de Lisboa:

- Servicos $9^{\circ}$ Texto Integral @ b-on

- $\quad$ Download PDF (371.1 KB)

- View HTML

- Permissions \& Reprints

- Related

- Issue

- Journal

\section{Abstract}

A biomonitoring study, using transplanted lichens Flavoparmelia caperata, was conducted to assess the indoor air quality in primary schools in urban (Lisbon) and rural (Ponte de Sor) Portuguese sites. The lichens exposure period occurred between April and June 2010 and two types of environments of the primary schools were studied: classrooms and outdoor/courtyard. Afterwards, the lichen samples were processed and analyzed by instrumental neutron activation analysis (INAA) to assess a total of 20 chemical elements. Accumulated elements in the exposed lichens were assessed and enrichment factors (EF) were determined. Indoor and outdoor biomonitoring results were compared to evaluate how biomonitors (as lichens) react at indoor environments and to assess the type of pollutants that are prevalent in those environments.

\section{Keywords}

Lichens - Biomonitoring - Indoor environments - Air pollution - Rural and urban areas http://www.springerlink.com/content/52007u7723264678/ 